Volume 10, No.3, May - June 2021

International Journal of Advanced Trends in Computer Science and Engineering

Available Online at http://www.warse.org/IJATCSE/static/pdf/file/ijatcse821032021.pdf

https://doi.org/10.30534/ijatcse/2021/831032021

\title{
Optimization of Factorial Design with the type of Plackett-Burman Design to Study the Effects of Organic Rice Production Process: First Step Experiment
}

\author{
B. Surapong ${ }^{1}$, P. Suwattanarwong ${ }^{2}$ \\ ${ }^{1}$ Department of Industrial Technology, Faculty of Engineering, Rajamangala University of Technology Lanna, \\ Thailand, pong_pang49@yahoo.com, surapongb@edu.rmutl.ac.th \\ ${ }^{2}$ Department of Industrial Technology Educaton, Faculty of Science and Technology, Chiang Mai Rajabhat \\ University, Thailand, suwatwong_pha@cmru.ac.th
}

\begin{abstract}
The research aims at the optimization to determine factors production process of the of the output organic rice so that the best possible set of parameters affecting it can be selected to get the desired output. For this purpose, the effect of various parameters on the organic rice output is studied. To facilitate the study and detailed analysis, a statistical model is constructed which is used to predict and optimize the performance of the system. Efficient organic rice optimization determines the input variable settings to adjust the organic rice of the organic rice according to the consumption of the parts in the next phase of production process. To study the interaction among the factors a 36 factorial experiment approach has been adopted using the two basic principles of experimental design replication and randomization. The process model was formulated based on analysis of variance (ANOVA) and regression of coefficient using Minitab Release 19.00. The output is represented graphically and in the form of empirical model which defines the performance characteristics of the production process of organic rice by factorial design type of Placket-Burman design.
\end{abstract}

Key words: Factorial design, Plackett-Burman ANOVA, regression of coefficient, optimization, production process, organic rice

\section{INTRODUCTION}

The quality of peeled rice is depending on many factors such as rice strain, the rate of feeding, clearance between a rubber to rubber cylinder and paddy moisture content which usually are controlled not to be exceed $14 \%$ [1], [2]. In rice milling, the bran layers and germ removed during polishing are high in fiber, vitamins and minerals as well as protein. Their removal results in loss of nutrients, especially in substantial losses of $\mathrm{B}$ vitamins. Polishing rice reduces the thiamin content of rice by over $80 \%$. Parboiled rice is therefore higher in $\mathrm{B}$ vitamins than raw milled rice [3].
The enhancement of rice supply is another advantage of brown rice relative to polished or white rice. Post-harvest researchers say that the milling recovery in brown rice is $10 \%$ higher than polished rice [4]. There is the other benefit of brown rice - economics the fuel savings in milling is 50-60\% because the polishing and whitening steps are eliminated. It follows that the milling time is also shortened; labor is less; and the cost of equipment (if the mill is dedicated to brown rice) is much lower because the miller doesn't have to install polishers and whiteners [5].

Milling strips off the bran layer, leaving a core comprised of mostly carbohydrates [6]. In this bran layer resides nutrients of vital importance in the diet, making white rice a poor competitor in the nutrition game the following chart shows the nutritional differences between brown and white rice. Fiber is dramatically lower in white rice, as are the oils, most of the $\mathrm{B}$ vitamins and important minerals [7]. Brown rice (hulled rice) is composed of surface bran (6-7\% by weight), endosperm (E90\%) and embryo (2-3\%), [8]. White rice is referred to as milled, polished or whitened rice when $8-10 \%$ of mass (mainly bran) has been removed from brown rice [7]. During milling, brown rice is subjected to abrasive or friction pressure to remove bran layers resulting in high, medium or low degrees of milling depending on the amount of bran removed [7]-[10]. Milling brings about considerable loss of nutrients and affects the edible properties of milled rice [7]-[10]. As most cereals, rice does not show a homogeneous structure from its outer (surface) to inner (central), [11]. As a consequence, information on the distribution of nutrients will greatly help in understanding the effect of milling and aid in improving sensory properties of rice while retaining its essential nutrients as much as possible [12].

Therefore, the purpose of this research is to generate between clearance of rubber and spindle of speed of rice using Design of Experiment (DOE) by factorial design with type of plackett-burman design in order to generate the suitable factors. For some parameter optimization on organic rice. 
B. Surapong et al ., International Journal of Advanced Trends in Computer Science and Engineering, 10(3), May - June 2021, 2080 - 2084

\section{EXPERIMENTAL DESIGN}

\subsection{Factorial Design of Experiments}

Optimum conditions are decided by changing several factors at once and using different levels of these factors. Factorial designs are widely applied in the experiments that are taking into account several factors where it is necessary to study the interaction effect of factors on the response [13]. $2^{k}$ factorial design of experiments needs a smaller number of experiments for several factors; thus, materials and time used are slightly reduced [14],15]. When factorial design methods applied to experiments of a process, mathematical models are derived through obtained variance analysis tables. Experiments are chosen randomly to prevent partiality of researchers [16].

The factorial design with type of design Placket-Burman design describes which factor shows more impact and influences the variation of one factor on the other factors [17]. The two factors; spindle of speed (SS) and the rubber of clearance (CL), respectively were varied at two levels as given in (see Table 1) to investigate their effects on response.

Table 1: Factors and levels for organic rice production experiment

\begin{tabular}{|lccc|}
\hline Parameter & Variable & Lower Limit & Upper Limit \\
\hline $\begin{array}{l}\text { Spindle } \\
\text { of speed, SS }\end{array}$ & $\mathrm{X}_{1}(\mathrm{RPM})$ & 1,420 & 1,460 \\
$\begin{array}{l}\text { Rubber of } \\
\text { clearance, CL }\end{array}$ & $\mathrm{X}_{2}(\mathrm{~mm})$. & 1.0 & 1.2 \\
\hline
\end{tabular}

Table 2: Design matrix for DOE $2^{\mathrm{k}}$ factorials

\begin{tabular}{|c|c|c|c|c|c|}
\hline Run Order & Pt Type & Blocks & $\mathrm{X}_{1}$ & $\mathrm{X}_{2}$ & RESPONSE \\
\hline 1 & 1 & 1 & 1 & -1 & 75.360 \\
\hline 2 & 1 & 1 & 1 & -1 & 75.300 \\
\hline 3 & 1 & 1 & -1 & -1 & 88.410 \\
\hline 4 & 1 & 1 & 1 & -1 & 75.330 \\
\hline 5 & 1 & 1 & -1 & 1 & 81.040 \\
\hline 6 & 1 & 1 & -1 & -1 & 87.210 \\
\hline 7 & 1 & 1 & -1 & 1 & 82.115 \\
\hline 8 & 1 & 1 & 1 & 1 & 70.220 \\
\hline 9 & 1 & 1 & 1 & -1 & 76.420 \\
\hline 10 & 1 & 1 & 1 & 1 & 70.180 \\
\hline 11 & 1 & 1 & -1 & 1 & 80.020 \\
\hline 12 & 1 & 1 & -1 & -1 & 88.400 \\
\hline 13 & 1 & 1 & 1 & 1 & 70.420 \\
\hline 14 & 1 & 1 & -1 & 1 & 80.936 \\
\hline 15 & 1 & 1 & -1 & -1 & 89.210 \\
\hline 16 & 1 & 1 & -1 & -1 & 90.100 \\
\hline 17 & 1 & 1 & -1 & 1 & 79.910 \\
\hline 18 & 1 & 1 & 1 & -1 & 75.490 \\
\hline 19 & 1 & 1 & -1 & -1 & 90.210 \\
\hline 20 & 1 & 1 & 1 & 1 & 70.380 \\
\hline 21 & 1 & 1 & -1 & -1 & 89.990 \\
\hline 22 & 1 & 1 & 1 & -1 & 79.410 \\
\hline 23 & 1 & 1 & -1 & 1 & 79.380 \\
\hline 24 & 1 & 1 & 1 & 1 & 70.420 \\
\hline 25 & 1 & 1 & 1 & 1 & 70.810 \\
\hline 26 & 1 & 1 & 1 & -1 & 78.990 \\
\hline 27 & 1 & 1 & -1 & 1 & 80.020 \\
\hline 28 & 1 & 1 & -1 & -1 & 86.450 \\
\hline 29 & 1 & 1 & -1 & 1 & 79.490 \\
\hline
\end{tabular}

Table 2: (Cont.) Design matrix for DOE 2k factorials

\begin{tabular}{|lrrrrc|}
\hline Run Order & Pt Type & Blocks & X1 & X2 & RESPONSE \\
\hline 30 & 1 & 1 & -1 & 1 & 82.115 \\
\hline 31 & 1 & 1 & 1 & 1 & 70.090 \\
\hline 32 & 1 & 1 & 1 & 1 & 70.810 \\
\hline 33 & 1 & 1 & 1 & -1 & 75.210 \\
\hline 34 & 1 & 1 & 1 & 1 & 70.410 \\
\hline 35 & 1 & 1 & 1 & -1 & 75.380 \\
\hline 36 & 1 & 1 & -1 & -1 & 90.280 \\
\hline
\end{tabular}

The $2^{k}=36$ factorial with three replicated treatment combinations were performed. Note that 36 samples were made at the coded treatment combination $(0,0)$. The observed percentage of good rice ranged from 70.090 to $90.280 \%$. Table 2 presents the results for all $2^{k}=36$ runs, run order by response. Therefore, thirty- six observations were taken in all to employ factorial design type of Plackett-Burman design as shown in (see Table 2).

Throughout the experiment it was assumed that: the factor is fixed; the design was completely randomized and the usual normality assumptions of the data were satisfied.

\subsection{Statistical Methods and Software}

The analysis and results of the experimental design were studied and interpreted by MINITAB RELEASE 19.00 (PA, USA licensed to Department of Industrial Engineering, Faculty of Engineering, Rajamangala University of Technology Lanna, Chiang Mai, Thailand) statistical software to estimate the response of the dependent variable. The response curves and contour plots are also generated. After production process of organic rice, the response was calculated and analyzed using regression coefficient analysis and analysis of variance (ANOVA).

\subsection{Hypothesis}

Definition of Statistical hypothesis

Statistical hypothesis that are evaluated by appropriate statistical techniques.

There are two hypotheses involved in hypothesis testing

- Null hypothesis $H_{0}: \mu_{1}=\mu_{2} \quad$ (there is not significantly different in mean the percentage of good rice).

- Alternative hypothesis $H_{1}: \mu_{1} \neq \mu_{2}$ (at least one different in mean the percentage of good rice).

The level of significance $(\alpha)$ is a probability and, in fact, is a probability of rejecting a true null hypothesis.

The level of significance $(\alpha)$ are as follows:

If the p-value $<\alpha$, then reject $\mathrm{H} 0$ that means there are at least one level significantly different.

If the p-value $\geq \alpha$, then failed to reject $H_{0}$ that means no significantly different. 
B. Surapong et al ., International Journal of Advanced Trends in Computer Science and Engineering, 10(3), May - June 2021, 2080 - 2084

\section{RESULTS AND DISCUSSION}

\subsection{Results}

The DOE simulation was accomplished with two parameters: spindle of speed and rubber of clearance respectively. It was performed according (see Table 1 and 2), and of main effects for the response as shown in Figure 1. A model fitting was accomplished for the first $2^{k}$ factorial design with type of Plackett-Burman design (see Table 1). The independent (SS and $\mathrm{CL}$ ) and the dependent variables were fitted to the second-order model equation and examined in terms of the goodness of fit. The analysis of variance (ANOVA) was used to evaluate the adequacy of the fitted model. The R-square value (determination coefficient) provided a measure of how much of the variability in the observed response values could be explained by the experiment factors and their interactions. (see Table 1) shows the results according to simulated analysis performed in MINITAB Release 19.00 used for simultaneous optimization of the multiple responses.

The desired goals for each variable and response were chosen. All the independent variables were kept within range while the responses were either maximized or minimized. The significant terms in different models were found by analysis of variance (ANOVA) for each response. Significance was judged by determining the probability level that the F-statistic calculated from the data is less than $5 \%$. The model adequacies were checked by $R^{2}$, adjusted- $R^{2}\left(\operatorname{adj}-R^{2}\right)$. The coefficient of determination, $R^{2}$, is defined as the ratio of the explained variation to the total variation according to its magnitude. It is also the proportion of the variation in the response variable attributed to the model and was suggested that for a good fitting model, $\mathrm{R}^{2}$ should not be more than 75 $\%$. The calculated value is greater than the value in the table and therefore accepts the results that are significantly different at the confidence level ( $\mathrm{p}$-value $<\alpha, 0.005<0.05$ ), (SS x CL) for source model and two-way interactions. A good model should have a large $R^{2}$, adj- $R^{2}$. Response surface plots were generated with MINITAB Release 19.00. The results of the above experiments then conducted analysis of variances (ANOVA) to determine the influence of factors on the response (see Table 3).

Table 3: Analysis of variance ( $95 \%$ confidence)

\begin{tabular}{|l|c|l|l|l|l|}
\hline Source & DF & Adj SS & Adj MS & F-Value & P-Value \\
\hline Model & 3 & 1634.8 & 544.95 & 368.00 & 0.000 \\
\hline Linear & 2 & 1621.2 & 810.65 & 547.42 & 0.000 \\
\hline SS & 1 & 1163.4 & 1163.4 & 785.66 & 0.000 \\
\hline CL & 1 & 457.85 & 457.85 & 309.18 & 0.000 \\
\hline $\begin{array}{c}\text { 2-Way } \\
\text { Interactions }\end{array}$ & 1 & 13.55 & 13.55 & 9.15 & 0.005
\end{tabular}

Table 3: (cont.) Analysis of variance (95\% confidence)

\begin{tabular}{|l|c|c|c|c|c|}
\hline Source & DF & Adj SS & Adj MS & F-Value & P-Value \\
\hline SS*CL & 1 & 13.55 & 13.55 & 9.15 & 0.005 \\
\hline Error & 32 & 47.39 & 1.48 & & \\
\hline Total & 35 & 1682 & & & \\
\hline \multirow{2}{*}{ Model summary } & S & R-sq & R-sq(adj) & $\begin{array}{c}\text { R-sq } \\
\text { (pred) }\end{array}$ \\
\cline { 2 - 6 } & 1.2169 & $97.18 \%$ & $96.92 \%$ & $96.4 \%$ \\
\hline
\end{tabular}

\subsection{Hypothesis Testing}

An alternative decision rule using the $\mathrm{p}$ - value definition. The $p$-value is defined as the smallest value of $\alpha$ for which the null hypothesis can be rejected.

If the p-value is less than or equal to $\alpha$, we reject the null hypothesis $(\mathrm{p}<\alpha)$.

If the p-value is greater than $\alpha$, we do not reject the null hypothesis $(\mathrm{p} \geq \alpha)$.

\subsubsection{Spindle of Speed Factor}

For the response, the value of $\mathrm{p}$ was 0.000 . Thus, the conclusion is rejecting $H_{0}$, which means there are significant differences between the levels in the $p$. The response is shows that the response significant effect on production process of organic rice.

\subsubsection{Clearance Factor}

For the response, the value of $p$ was 0.000 . Thus, the conclusion is rejecting $H_{0}$, which means there are significant differences between the levels in the $p$. The response is shows that the response significant effect on production process of organic rice.

\subsubsection{Spindle of Speed and Clearance (Two-Way Interaction)}

For interaction with the spindle of speed and clearance the value of $p$ was 0.005 . So, the conclusion is rejecting $H_{0}$, which means there are significant differences between the levels spindle of speed and clearance. The differences of response between level of each factor as shown in Figure 1 and mean of response of each level (see Table 3 and Table 4).

While the remaining interaction the $p \geq \alpha$ which means there is significant difference between the level of the spindle of speed and clearance interaction. This suggests that the spindle of speed, and clearance are significant effect of response in production process of organic rice. 
Figure 1 shows the main effects of the two factors $\left(X_{1}\right.$ and $\left.X_{2}\right)$ response. The effect of a factor is the change in response produced by the change in level of factor. This is frequently called a main effect as it refers to the primary factor of interest in the experiment [18]. It was concluded that the larger the vertical line is Figure 1, the larger the change in of response when it is changing from level -1 to level +1 . Please note that the statistical significance of a factor is directly related to the length of the vertical line [19].

Table 4: Code coefficients $2^{\mathrm{k}}$ design)

\begin{tabular}{|l|l|l|c|c|c|l|}
\hline Term & Effect & Coef & SE Coef & T-Value & P-Value & VIF \\
\hline Constant & & 79.053 & 0.203 & 389.78 & 0.000 & \\
\hline SS & -11.370 & -5.685 & 0.203 & -28.03 & 0.000 & 1.00 \\
\hline CL & -7.132 & -3.566 & 0.203 & -17.58 & 0.000 & 1.00 \\
\hline SS*CL & 1.227 & 0.613 & 0.203 & 3.02 & 0.005 & 1.00 \\
\hline
\end{tabular}

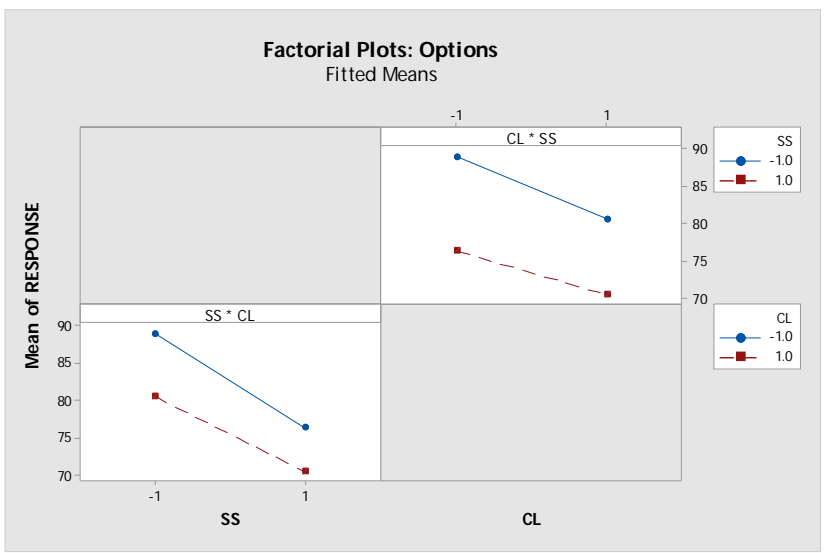

Figure 1: Plots of main effects for the response.

Analysis of variance is a statistical method that partitions the total variation into its component parts each of which is associated with a different source of variation [17]. The interaction effects are easily estimated and tested by using the usual ANOVA. The ANOVA results of the response were shown in (see Table 2). The sum of the squares used to estimate factors affect and Fisher's $F$ ratios (defined as the ratio of mean square effect and the mean square error) and $p$ values (defined as the level of significance leading to the rejection of the null hypothesis) were also represented.

The individual and interaction effects was given by the pareto chart of the standardized effects in as shown in Figure 2. In order to identify whether the calculated effects were significantly different from zero, Student's $t$-test was performed and horizontal columns in Pareto chart showed these values for each effect. For a 95\% confidence level and seven degrees of freedom $t$ value was equal to 2.04. The minimum statistically significant effect magnitude for $95 \%$ confidence level is represented by the vertical line in the chart. Four values higher than $2.04(P=0.05)$ were located at right of the dash line and were significant.

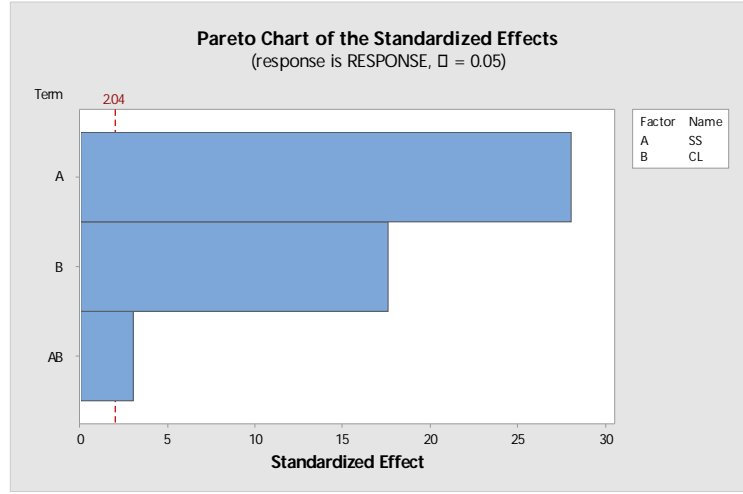

Figure 2: Pareto chart of standardized effects on the response

\section{CONCLUSIONS}

A factorial experiment design type of Plackett-Burman design has been developed which can be used for the optimization of output organic rice of the production process of the organic rice. Such a model not only assists to estimate the magnitude and direction of the effects of change in factors but also predicts the effects of their mutual interactions.

The experimental results show that the spindle of speed and clearance factor did not have a significant effect on the response. The spindle of speed and clearance has a significant impact on the response. The optimal level of spindle of speed and clearance are $1,420 \mathrm{rpm}$ and 1.00 millimeters respectively. Production process of organic rice at this level will meet the requirement of Community enterprises. The response with the two-level selected of organic rice can be modeled using the factorial design with type of PlackettBurman design, as well as the response surface regression method. The value of $R^{2}(86.85 \%)$ and $R^{2}$ adj $(85.61 \%)$ of the obtained models show that the models fit all the cases.

The significant effect of independent factors was analyzed using ANOVA, and the effect was also reported in the form of maim effects plots. The design of experiments provides efficient tools for the optimization of variable factors for general by factorial design type of Plackett-Burman design.

\section{ACKNOWLEDGEMENTS}

Financial support department of Industrial technology education, faculty of Engineering RMUTL: Rajamangala University of Technology Lanna, Chiang Mai, Thailand and department of Industrial technology educaton, Faculty of science and technology, Chiang Mai Rajabhat University, Thailand is gratefully acknowledged. 


\section{REFERENCES}

1. S. Bangphan and S. Lee. Modeling material mixtures to replace of rice polishing cylinder, Proceeding of the Conference of Industrial Engineering, IE network conference, Bangkok, Thailand, 17-19 December 2006.

2. S. Bangphan, S. Lee and S. Jomjunyong. Development of the Alternative composite material for rice polishing cylinder, Proceeding 8th, Conference APIEMS \& CIIE 2007, Industrial Engineeris, Kaohsiung, Taiwan, 9-12 December 2007.

3. Oh. C.H. and S.H. Oh. Effects of germinated brown rice extracts with enhanced levels of GABA on cancer cell proliferation and apoptosis, Journal of Medical Food, 2004, vol.7, no1.

4. Garrow J.S. et al. Human nutrition and dietetics, Harcourt Publishers, London,2000.

5. Rogelio V. Cuyno. The national campaign to combat hidden hunger through brown rice paper presented during consultative meeting on nutritional aspect of brown rice, at Food \& Nutrition Research Institute., Manila Philippines,2003.

6. S. Bangphan., P. Bangphan, and T.Boonkang. Implementation of response surface methodology using in small brown rice peeling machine : part I, World Academy of Science, Engineering and Technology; ICIKM 2013 : International Conference on Information and Knowledge Management, Barcelona, Spain, 27-28 February 2013.

7. Wood Rebecca. The whole foods encyclopedia, New York, NY: Prentice-Hall Press, 1988.

8. Chen H. and Siebenmorgen T.J. Effect of rice thickness in degree of milling and associated optical measurements, Cereal Chemistry, 1997, no. 74, pp. 821-825.

9. Chen H., Siebenmorgen T.J. and Griffin, K.

Quality characteristics of long-grain rice milled in two commercial systems, Cereal Chemistry, 1998, vol. 75, 560-565.

10. Kennedy G., Burlingame B. and Nguyen N. Nutrient impact assessment of rice in major rice-consuming countries, International Rice Commission Newsletter, 2002, no.51, pp.33-41.

11. Itani T., Tamaki M., Arai E. and Horino T. Distribution of amylose, nitrogen, and minerals in rice kernels with various characters, Journal of Agricultural and Food Chemistry,2002, vol. 50, pp. 5326-5332.

12. Jianfen Liang et al. Milling characteristics and distribution of phytic acid and zinc in long-,mediumand short-grain rice, Journal of Cereal Science, 2008, vol. 48, pp. 83- 91.

13. K. E. Lee, N. Morad, T. T. Teng, and B. T. Poh. Factorial experimental design for reactive dye flocculation using inorganicorganic composite polymer, APCBEE Procedia, 2012, vol. 1, pp. 59- 65.
14. G. Annadurai, R.-S. Juang, and D.-J. Lee. Factorial designanalysis for adsorption of dye on activated carbon beads incorporated with calciumalginate, Advances in Environmental Research, 2002, vol. 6, no. ,pp. 191-198.

15. V. Ponnusami, V. Krithika, R. Madhuram, and S. N. Srivastava. Biosorption of reactive dye using acidtreated rice husk: factorial design anlysis, Journal of Hazardous Materials, 2007, vol.142, no.1-2,pp.397-403.

16. N. Özbay, A. F. YargJç, R. Z. Yarbay-Fahin, and E. Önal. Full Factorial Experimental design analysis of reactive dye removal by carbon adsorption, Journal of Chemistry, Volume 2013, Article ID 234904, 13 pages, 2013.

17. Y. Safa and H. N. Bhatti. Adsorptive removal of direct textile dyes by low cost agricultural waste: application of factorial design analysis, Chemical Engineering Journal, 2011, vol. 167, no. 1, pp. 35-41.

18. A. Rathinam, J. R. Rao, and B. U. Nair. Adsorption of phenol onto activated carbon fromseaweed: determination of the optimal experimental parameters using factorial design, Journal of the Taiwan Institute of Chemical Engineers, 2011, vol. 42, no. 6, pp. 952-956.

19. D. Bingol,N. Tekin, andM. Alkan. Brilliant yellow dye adsorption onto sepiolite using a full factorial design, Applied Clay Science, 2010, vol. 50, no. 3, pp. 315-321. 